\title{
Exploring Preservice Teachers' Computational and Representational Knowledge of Content and Teaching Fractions
}

\author{
ROSLI, Roslinda \\ College of Education, National University of Malaysia, 43600 Selangor, \\ Malaysia; Email: roslinda@ukm.my \\ HAN, Sunyoung* \\ Department of Curriculum and Instruction, Texas Tech University, \\ Lubbock, TX 79409-107, USA; Email: sunyoung.han@ttu.edu \\ CAPRARO, Robert M. \\ Department of Teaching, Learning and Culture, Texas A\&M University, \\ College Station, TX 77843; Email: rcapraro@tamu.edu \\ CAPRARO, Mary M. \\ Department of Teaching, Learning and Culture, Texas A\&M University, \\ College Station, TX 77843; Email: mmcapraro@tamu.edu
}

(Received September 3, 2013; Revised December 20, 2013; Accepted December 25, 2013)

The data for the present paper was a part of a large research project conducted to assess preservice teachers' knowledge related to fractions and place value at a southwestern public university in 2007. The study utilized convenience sampling, consisting of $150 \mathrm{el}-$ ementary preservice teachers who were enrolled in a mathematics methods course before their student teaching. The results demonstrated preservice teachers' knowledge of teaching comparison, addition, subtraction, and multiplication of fractions was insufficient even though these should be basic knowledge. Teacher preparation programs should emphasize profound knowledge for teaching fractions using representations.

Keywords: fractions, teacher education, pedagogical content knowledge MESC Classification: D60, H20

MSC2010 Classification: $97 \mathrm{E} 50$

* Corresponding author 


\section{INTRODUCTION}

The National Council of Teachers of Mathematics' Principles and Standards for School Mathematics (NCTM, 2000) stated fractions were fundamental because of their significant application in daily-life contexts. In addition, understanding fractions expands the ability to learn subsequent mathematical concepts within such broad disciplines as algebra, trigonometry, and calculus. However, a large body of literature has shown that learning fractions is complex (e.g., Ball, 1990; Empson, 2002; Lamon, 1999; Ma, 1999; Mewborn, 2003). For example, the following open-ended contextual problem was administered to twelfth graders (National Assessment of Educational Progress [NAEP], 2005):

In a certain restaurant a whole pie has been sliced into 8 equal wedges. Only 2 slices of the pie remain. Three people would each like an equal portion from the remaining slices of pie. What fraction of the original pie should each person receive?

Only $22 \%$ of the participants were able to give the correct short response answer $\frac{1}{12}$, whereas $67 \%$ were wrong and $9 \%$ omitted the problem.

The purpose of this study was to explore preservice teachers (PTs)' knowledge of the computations and representations of fractions and to investigate the relationship between content and teaching knowledge. Even though there have been many studies indicating PTs' insufficient knowledge on the fractions' computations; the present study was unique in that PTs' knowledge was examined especially associated with the teaching knowledge (i.e., representation skills) as well as content knowledge (i.e., computation skills), and the relationship between computation and representation skills.

\section{Constructing Fraction Concept}

The teaching of fractions is rife with mnemonics, patterns, and shortcuts, often taught by teachers, which may lead to fundamental misunderstandings for students. Some of the shortcuts are processes and procedures to compute specific arithmetic operations with fractions that are not generalizable (Cramer, Post \& delMas, 2002). For example, students learned to use new rules or algorithm such as invert and multiply, for dividing fractions but then tended to use it in other situations where it was inappropriate (Miller \& Hudson, 2006). When students learned to compare fractions they could have been taught to use the butterfly method. This method works well for determining if the fractions are equivalent; however, students might just memorize the rules and apply them inappropriately as in the second one in Figure 1. Unfortunately, students then devise rules for determining which fraction is larger based on the butterfly method that often results in decisions that are no better than chance (Cramer, Post \& delMas, 2002). Basing instruction on rules may hinder a deep understanding of the rational number system. 


$$
\begin{aligned}
& 2 \times 5=10 \quad \frac{2}{3} \times \frac{4}{5} \quad 3 \times 4=12 \\
& 3 \times 4=12 \quad \frac{2}{3} \times \frac{4}{5} \quad 2 \times 5=10
\end{aligned}
$$

Figure 1. Butterfly method

When students are starting to learn about fractions, they are constructing their understanding of a different type of number system (e.g., $\frac{2}{2}, \frac{1}{3}, \frac{4}{3}, 2 \frac{1}{2}$ ) with its own representations and symbols (Wright, 2008). Fractions, unlike whole numbers with which students have a better understanding, requires relational fluency and is based on a comparison or ratio with a specified unit referent (Cramer, Behr, Post \& Lesh, 1997). It is important for students to build new knowledge by connecting to their prior knowledge (Vygotsky, 2009), which facilitates a smooth transition to learning the rational number systems (Empson, 2002). Students should be shown operations with fractions in concrete terms (Martin \& Sebesta, 2004; Patterson, Capraro, Kemp, Standish \& Sun, 2003) at the onset or introduction of the concepts (Naiser, Wright \& Capraro, 2004). Therefore, it is important for teachers to support students' rational number development throughout operations with fractions.

\section{Representation of Fractions}

The final goal in classrooms regarding fractions should be to help students to develop a deep understanding through using varied representations of fraction in order to become more successful in advanced mathematics such as calculus. However, students' representational skills have been known to be different from computational skills and difficult to be learned (Lamon, 2001). The representational skills of fractions are indicative of being able to explain algebraic logics using symbols, verbal words, figures, or manipulative activities (Kiren, 1980). Students are required to have a robust algebraic understanding of fractions in representing fractional arithmetic with diverse representational skills. On the other hand, it is easy to look at students who can compute fractions using addition, subtraction, multiplication, and division and not being able to represent and explain what the meaning is and how to express the procedure (Lamon, 2001). Most students just memorize and follow computational algorithms of fractions.

The representations of fraction and fractional arithmetic can improve students' robust understanding of fractions. Fractions are different from natural numbers or rational numbers in terms of the many more meanings of relative amount or ratio, which also applies to fractional computation (Lamon, 2001). For example, students as well as teachers may 
know well the arithmetic of $2 \times 3$ and can imagine how to represent this arithmetic expression with verbal words or figures. However, in the case of multiplication of fractions, $\frac{1}{2} \times \frac{2}{3}$, teachers may know how to calculate it; but not be familiar with representations to help students understand fractions by explaining why the answer is $\frac{1}{3}$ or being able to show the procedure for this arithmetic.

The issue associated with teaching fractions caused from the limited pedagogical approaches by teachers as well as students' learning experiences has been neglected for a long time (Lamon, 2001). Many curriculum materials such as textbooks and teachers' original handouts were focused on providing more rote problems to practice students' computational skills than manipulative activities with arithmetic (Capraro, Capraro, Younes, Han \& Garner, 2010; Han, Rosli, Capraro \& Capraro, 2011). In addition, teachers' lack of content and pedagogical knowledge of fractions has also been pointed out as a critical reason for failure to provide students opportunities for diverse learning experiences with fractions (Baumert et al., 2010; Hill, Rowan \& Ball, 2005). Teachers were not prepared to teach students with varied representations of fractions and arithmetic in schools. We assume that teachers' insufficient knowledge may hinder students' robust understanding of fraction and fractional representation.

\section{Relationship of the Teachers to Learning Process}

Even though the majority of preservice and inservice teachers can solve arithmetic operations involving fractions correctly, they often have difficulty comprehending the meaning conceptually (Ma, 1999). Division of fraction was one such example where teachers were not able to easily conceptualize the meaning (Ball, 1990). That is, a majority of preservice elementary and secondary teachers' could not explain the underlying meanings and principles of $1 \frac{3}{4} \div \frac{1}{2}$. While they were able to compute the final answer correctly they were unable to provide a meaningful mathematical explanation to show conceptual understanding (Ma, 1999). It was suggested that they may actually be efficient with the rule "invert and multiply", but lack a rigorous facility with the concept. Unfortunately, there may be a cyclical relationship between how something is learned and how one may teach it.

Inservice teachers' knowledge of teaching has been based on what they learned as students. Therefore, inservice teachers teach students with similar strategies as they were taught (Koballa, Glynn \& Upson, 2005; Simmons et al., 1999). In other words, teachers' pedagogical content knowledge is deeply rooted in their prior experience. For example, some PTs had problems with fraction concept in secondary school and may continue through post secondary school without any remediation. If PTs do not receive constructive feedback about fractional misconceptions during university level courses, they will 
bring their incorrect conceptions to their classrooms. Finally, the cyclical process of students' misconception to PTs' misconceptions to inservice teachers' misconceptions and finally back to students does affect how students learn fractions (Ball, Hill \& Bass, 2005; Baumert et al., 2010; Hill, Rowan \& Ball, 2005).

During fraction instruction, when a teacher focused on procedural understanding, students may have learned the ideas algorithmically without fully understanding the principles conceptually (Miller \& Hudson, 2006). Even though algorithmic strategies (e.g., butterfly method, invert and multiply) seemed efficient and easy to operate, many scholars strongly believed that teachers should not introduce fractions based on rules and algorithms (Cramer, Post \& delMas, 2002; Miller \& Hudson, 2006; Van de Walle, Karp \& Bay-Williams, 2010). In school, teachers should first explain and teach the basic fraction knowledge using concrete representational models. For instance, when instructing students on fraction division $\frac{1}{2} \div \frac{1}{3}$, teachers must show how to use concrete models such as paper folding and fraction strips to represent the concepts to the students (Cramer \& Wyberg, 2009). Then, teachers should nurture students' conceptual development from concrete model to pictorial representational model and make sure their students understand the concept meaningfully (Cramer \& Wyberg, 2009; Diezmann \& English, 2001; Miller \& Hudson, 2006). The arithmetic operation $\frac{1}{2} \div \frac{1}{3}$ means, "How many sets of $\frac{1}{3}$ are in $\frac{1}{2}$ ?" (Van de Walle et al., 2010). Figure 2 shows a set of $\frac{1}{3}$ in $\frac{1}{2}$ and the remainder area was actually $\frac{1}{2}$ of $\frac{1}{3}$. There was a change of the unit whole from $\frac{1}{3}$ to 1 . Therefore, there was $1 \frac{1}{2}$ sets of $\frac{1}{3}$ in $\frac{1}{2}$. When students have mastered the idea conceptually, teachers could show a procedural process for obtaining the division value, $\frac{1}{2} \div \frac{1}{3}=\frac{1}{2} \times \frac{3}{1}=\frac{3}{2}=1 \frac{1}{2}$, which Skemp (1976) recognized as "turn it upside down and multiply" rule. It was important for teachers to help students to construct their own understanding developmentally and make a smooth transition from concrete to abstract representations (Cramer \& Wyberg, 2009; Miller \& Hudson, 2006; Van de Walle, Karp \& Bay-Williams, 2010).

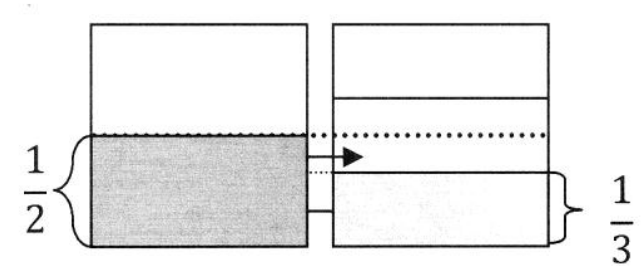

Figure 2. Models for fraction division

\section{Interrupting the Cycle with Pedagogical Content Knowledge}

Teachers are responsible for making the learning of fractions meaningful by finding a 
way to represent the topic to students of all ages (Shulman, 1986). The use of representations can be a powerful way to introduce abstract concepts in mathematics especially for younger students (Shulman, 1986). Further, the use of multiple representations (e.g., pictorial, concrete models, graphical, numerical) during mathematics instruction was closely linked with improved student learning of fractions (NCTM, 2000). "The key in fraction instruction is to pose tasks that elicit a variety of strategies and representations" (Empson, 2002, p. 39) and, that representational models used by teachers (e.g., pizzas, fraction tiles, number lines, and fraction bars) engaged and facilitated students' learning of initial fraction knowledge (Cramer, Post \& delMas, 2002; Cramer \& Wyberg, 2009). The Cycle of Fraction Learning and Teaching shown in Figure 3 is representative of the literature; thus it is important to study the cycle and interrupt it at a time point most likely to have the greatest impact.

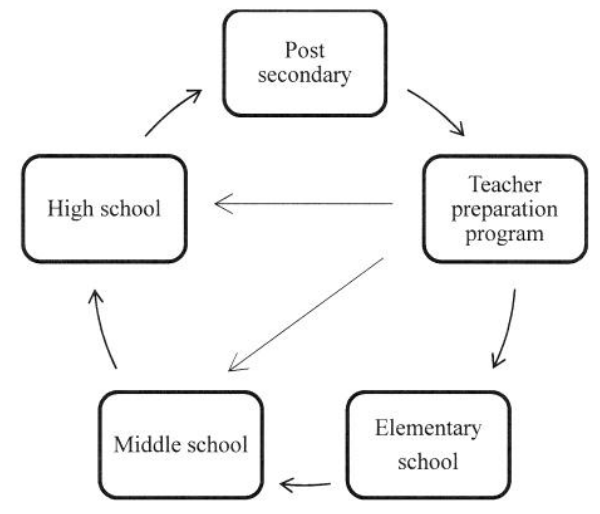

Figure 3. Cycle of learning and teaching fraction.

Studying teachers' knowledge for teaching fractions is indeed necessary because the nature of the topic is complex to learn and teach. Past and recent research studies have shown that teachers have insufficient knowledge of teaching fractions (Naiser, Wright \& Capraro, 2004). The knowledge for teaching fractions should have been acquired during their post secondary program (e.g., Ball, 1990; Newton, 2008; Tirosh, 2000). However, in most cases it is not. Developing pedagogical content knowledge (PCK) may play an important role in interrupting the cycle by making conceptual instruction explicit for PTs and demonstrating more meaningful ways to use fractional procedural knowledge.

One way of breaking of the cycle is to explicitly teach PTs fraction concepts based on the mathematical knowledge for teaching (MKT) framework. The MKT conceptual framework is a practice-based theory that presented six domains of teacher knowledge built on Shulman's PCK notion (Ball, Thames \& Phelps, 2008). Specifically, this study utilized one of the sub-domains from MKT, knowledge of content and teaching (KCT) 
that combines knowledge about mathematics and instruction. It refers to teacher's knowledge on a variety of instructional strategies to make a particular concept understandable to students (Ball, Thames \& Phelps, 2008). For this study, the researchers investigated PTs' mathematical and pedagogical understanding as they represented their knowledge for teaching fractions using various modes of representations.

\section{METHODS}

The data reported in this article was a part of a larger research study dealing with the Math Texas Essential Knowledge and Standards [TEKS] Connections (MTC). The MTC project created professional development opportunities for teachers focusing on producing deeper understanding of mathematics skill standards and the connections among those standards within and across grade levels. As part of the project, a study was conducted to assess the PTs' knowledge of teaching place value and fractions at a southwestern public university and to design a 4-week web-based module system for directly addressing the misconceptions related to fractions as well as the methods for teaching fractions conceptually. The web-based instrument includes interactive applications with fraction stripes and geoboards to show the four basic operations. The web-based instrument included constraints like, fractions summed to less than one and all operations used only two fractions. This particular part of the study focused on PTs' knowledge of fractions: comparison, addition, subtraction, and multiplication. The researchers also examined the PTs' ability to use mathematical representations while teaching fractions.

The study utilized a convenience sampling consisting of 150 elementary PTs from four different class sections (i.e., 501, 502, 503, 504). These PTs were in their senior year taking a mathematics methods course in preparation for student teaching after completion of the web-based instrument for developing PCK for fractions. The data were used to answer the following research questions:

a) To what extent could the PTs solve the problems involving comparison, addition, subtraction, and multiplication of fractions?

b) How did the PTs demonstrate their process for solving comparison, addition, subtraction, and multiplication of fractions with representations?

c) What was the relationship, if any, between the PTs computational ability and their ability to explain the process conceptually?

\section{Data Sources}

The data were gathered by using a fractions assessment exam, which was based on the 
MTC. Items tasks in the assessment were aligned to TEKS related to the comparison, addition, subtraction, and multiplication of fractions. The first and fourth items consisted of three sub-sections ( $a, b$, and $c$ ), of which the first and second parts assessed PTs' knowledge on comparison, subtraction, and addition of two fractions with unlike denominators. Whereas, the second and third items included two parts ( $a$ and $b$ ) that focused on fraction multiplication. In the last sub-section ( $b$ and/or $c$ ) of each item, PTs were required to show their understanding using representations to help students build conceptual understandings of fractions. The instrument included a non-contextual task (first item) with the remaining items using day-to-day activities to represent the concept of fractions. These contextual problems were related to the number of exam questions correct, measurement for building a desk, and total pizza eaten altogether. The specific items are displayed in Appendix A.

\section{Data Analysis}

The first two researchers graded all the items using a scale from 0 to 2 points based on the coding process (see Appendix B). Items (i.e., 1a, b, 2a, 3a, and 4a) involving fractional knowledge were rated as 0 if the answer or explanation was inappropriate/incorrect or no work was shown. For instance, when comparing two fractions (item 1a), the explanation was not appropriate if PTs used different unit wholes. One point was awarded if the item was incomplete (i.e. the common denominator [CD] was found without comparing for equivalent fractions). Two points was given if the item was completely correct (e.g., model picture with correct area and same unit wholes). Then, the graders scored items 1c, $2 b, 3 b, 4 b$, and $4 c$ as 0 if the PTs were unable to generate any representation or provided an inappropriate model (different unit wholes for item 1c). One point was used for incomplete representation such as used the same unit wholes but did not show clearly which one was bigger. For appropriate representation, 2 points were awarded when PTs used the same unit wholes that facilitated comparison of fractions. The percentages of the two graders' inter-rater reliability ranged from 0.77 to 0.94 for each of the class sections.

The data were entered into the Statistical Program for Social Science (SPSS) version 16.0 for computing the quantitative results. To help answer the research questions, frequencies, and percentages were calculated for each item. In addition, the researchers analyzed type of responses and categorized them into similar classification of strategies that PTs used to answer the questions. It was important to explore and discuss the most common processes and representational models used among PTs. Pearson correlations between two sets of points were used to examine the relationship between PTs' computational ability and their ability to explain the process conceptually using representation. The correlation coefficient, $r$, illustrated whether the relationships were direct, high, indi- 
rect, inverse, low, moderate, negative, perfect, positive, strong, and weak (Huck, 2008). Confidence intervals were computed for PTs' content and teaching knowledge based on their responses of comparison, addition, and multiplication problems. The confidence intervals were presented graphically and used to infer the differences between KCT using 'inference by eye' (Cumming \& Finch, 2005, p. 170).

\section{RESULTS}

The researchers in this study intended to make external statistical generalizations of the participants' pedagogical content knowledge of fraction to the whole population of elementary PTs at the southwestern university. Therefore, the data of 150 PTs were used to portray their knowledge of content and teaching fractions. These included PTs abilities to compute and solve comparison, subtraction, addition and multiplication of fractions. Also, the results illustrated the various types of representational models PTs used that demonstrated their conceptual understanding of fractions. Then, the relationship between their algorithmic process and the representation used were examined. The results were presented in the following section to answer the three research questions in sequence.

\section{Computational Ability}

When PTs were asked to show a process for comparing two fractions, $\frac{5}{7}$ and $\frac{2}{3}$, only $21 \%$ (32 of 150 PTs) received the full 2 points (see Figure 4) demonstrating their understanding of the concept. Of those 32, 27 PTs used an algorithmic procedure for finding the $\mathrm{CD}$ and equivalent fractions and showed clearly one fraction was larger than the other, $\frac{15}{21}>\frac{14}{21}$. Also, a few PTs (5 of 32) modeled a pictorial representation using the same unit wholes and correctly represented one area was bigger. Most of the PTs (79\%) received either 0 or 1 point, which portrayed their incorrect or partially correct responses. A large percentage of PTs $(60 \%)$ received 1 point because they could not compare the fractions after finding the $\mathrm{CD}$ and equivalent fractions or their model picture did not clearly show the comparison or process involved. Those who scored 0 point (18.7\%) modeled pictures with different unit wholes or could not find the $\mathrm{CD}$ and equivalent fractions.

The study revealed that a majority $(78 \%)$ of the PTs were able to correctly answer the total pizza eaten (i.e., $\frac{5}{6}+\frac{3}{4}=\frac{19}{12}$ ) task. Based on the CD that they found, the participants showed a procedural understanding of finding equivalent fractions, and then performed the addition without making any computational errors. Of the 24 PTs who received 0 points (i.e., incorrect), most of them either did not show their work or attempted a solution strategy unlikely to result in an admissible solution (e.g., added numerators and de- 
nominators). There were seven PTs who merely added numerators and denominators (e.g., $\frac{5}{6}+\frac{3}{4}=\frac{8}{10}$ ) similar to results reported by Newton (2008). In contrast, considering addition and subtraction were closely related operations, only $65(43.3 \%)$ of the PTs could find the equivalent fractions and calculate the difference between $\frac{5}{7}$ and $\frac{2}{3}$. Of the 47 PTs (30\%) who scored 1 point, 38 of them successfully found the CD and equivalent fractions but they did not subtract both values for finding the difference. The remaining 38 PTs $(26.7 \%)$ received 0 point for no work shown (25 PTs) or used an unclear verbal explanation (11 PTs).

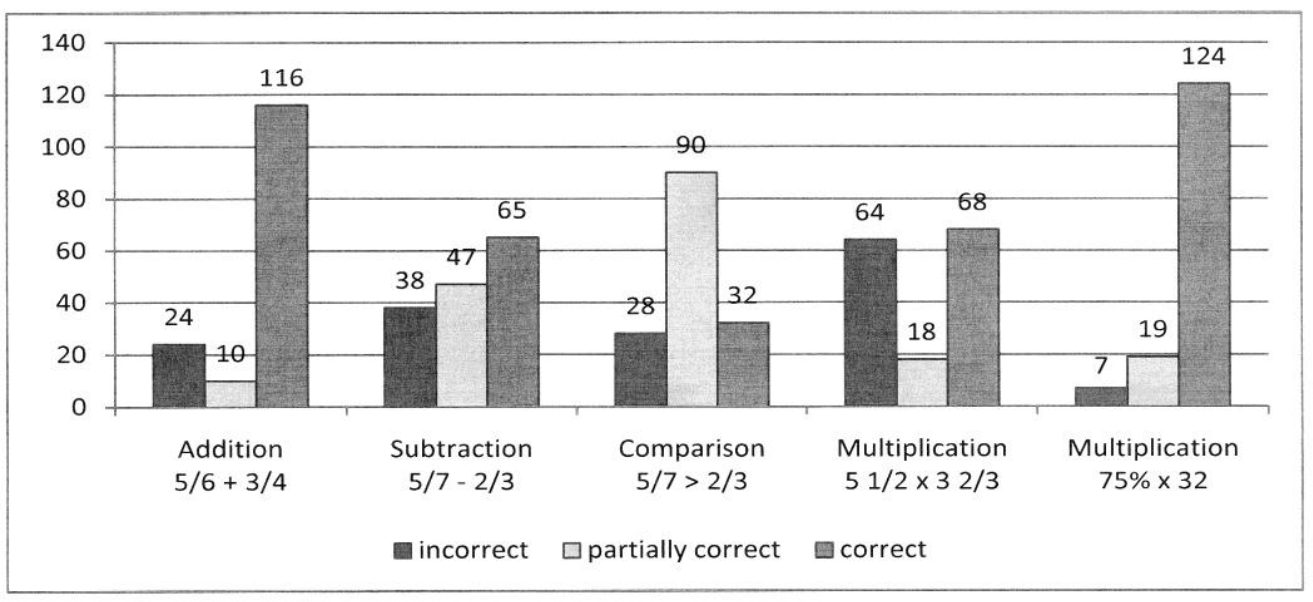

Figure 4. Analysis of computational processes

The results of this study showed that the two items involving multiplication were comparatively opposite as illustrated in Figure 4. When PTs were asked to solve $75 \% \times$ 32 , the majority $(82.7 \%$ ) could correctly determine the answer whereas only $45.3 \%$ (68 PTs) multiplied $5 \frac{1}{2}$ and $3 \frac{2}{3}$ successfully for full points. In the first case of multiplication, many PTs were able to use $75 \%$ or transform it into a simplified fraction, $3 / 4$ or decimal, 0.75 and then multiplied with 32 for the final solution. Meanwhile for the latter case, when multiplied $5 \frac{1}{2}$ and $3 \frac{2}{3}$ algorithmically, a majority (76.6\%) PTs made some errors during the process of finding the improper fractions (i.e., $\frac{11}{2}$ and $\frac{11}{3}$ ). There were a few PTs who found the $\mathrm{CD}$, equivalent fractions and then multiplied across numerators and denominators.

\section{Representations Used}

In order to answer the second research question, data on the types of representations used were examined closely with their categories. The study found only $42 \%$ (63 PTs) could correctly compare $\frac{5}{7}>\frac{2}{3}$ using an appropriate representation such as geoboard or 
fraction strips. However, after finding the $\mathrm{CD}$, they were able to illustrate $\frac{15}{21}$ was larger than $\frac{14}{21}$ by representing these fractions into the same unit wholes. About $23 \%$ (33 PTs) received 1 point because even though they represented the same unit wholes, they were not able to show one shaded area was larger than other. Thirty four percent (51 of 150 PTs) responded inappropriately because they used different unit wholes and noticeably uneven parts when comparing fractions.

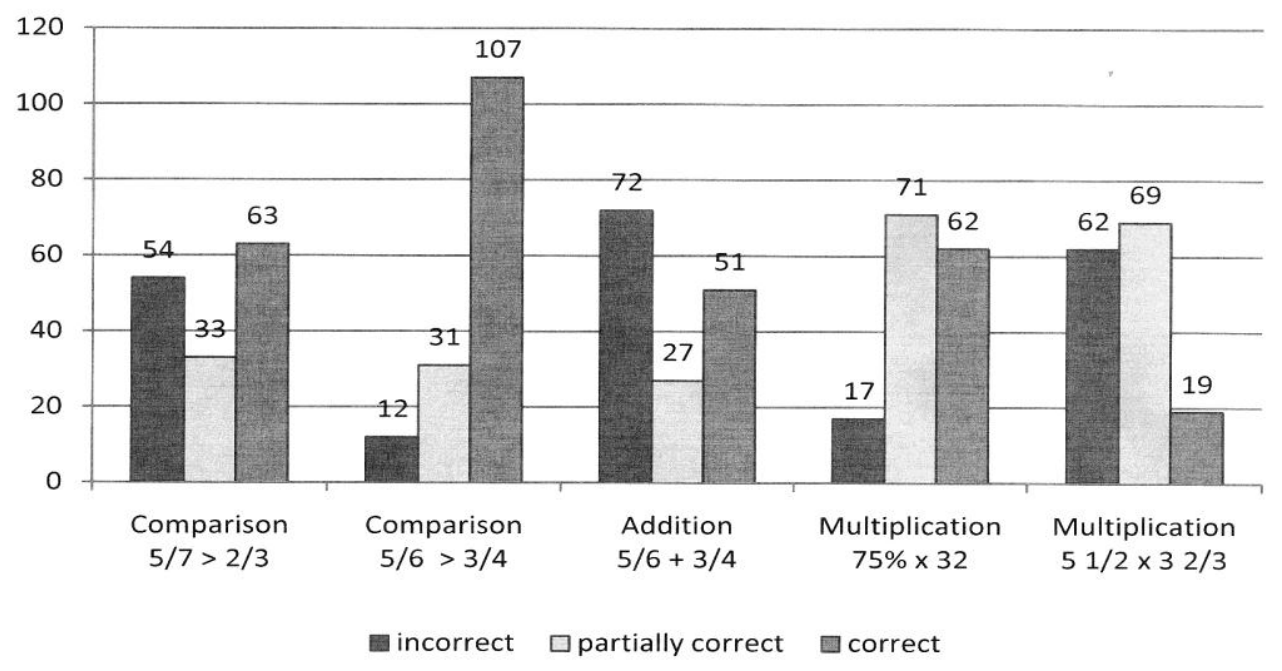

Figure 5. Analysis of representations used

Contrary to the first comparison task, most PTs $(71.3 \%)$ were able to conceptualize the comparison involving $\frac{5}{6}$ and $\frac{3}{4}$ (item $4 \mathrm{~b}$ ). In this case, PTs were presented a contextualized problem based on $\frac{5}{6}$ and $\frac{3}{4}$ of large pizzas eaten and they were asked to represent them specifically using fraction strips. Within the same task, PTs were also required to demonstrate their understanding of the addition operation $\frac{5}{6}+\frac{3}{4}$ by using a pictorial representation based on the least common denominator (LCD). The descriptive statistics showed only $34 \%$ (51 PTs) could represent the total pizza eaten as $1 \frac{7}{12}$. Most PTs drew and shaded one whole pizza and seven out of 12 pieces for another whole pizza. Then, $24.7 \%$ (37 PTs) showed no response and 23.3\% (35 PTs) attempted but did not provide appropriate representation, for example, using different unit wholes. For those who scored 1 point (18\%), most of them could provide a pictorial representation correctly, but they did not use the LCD as required by the task.

For the two problems involving multiplication of fractions, PTs' performances were similar across the two for those who were awarded 1 point. Even though they were able to generate a representation for both tasks (i.e., $75 \% \times 32$ and $5 \frac{1}{2} \times 3 \frac{2}{3}$ ), most of them were incomplete or inappropriate. For example, the multiplication task $75 \% \times 32$ (item 
2b) required the PTs to draw a fractions strip and shade 24 out of 32 equal parts showing the number of questions obtained in an exam. However, about $47.3 \%$ (71 PTs) used the number line, drew and shaded $3 / 4$ parts, or drew and shaded appropriate parts (24/32) without proper labeling.

On the other hand, only $12.7 \%$ (19 of 150 PTs) generated an appropriate visual model to portray the total area $\left(5 \frac{1}{2} \times 3 \frac{2}{3}\right)$ by dividing the rectangle into several parts for representing the fractions (Figure 7). The researchers believed this kind of model was more relevant than other representations such as a rectangular model. In fact, the results revealed that $46 \%$ (69 of 150 PTs) drew only a rectangle for representing the multiplication of fractions. About 35\% (52 of 150 PTs) generated inappropriate models by representing a length and width of the rectangle that was not proportionally correct, $5 \frac{1}{2}$ was smaller than $3 \frac{2}{3}$. The remaining 10 PTs $(6.3 \%)$ were not able to provide any kind of visual representations for this task.

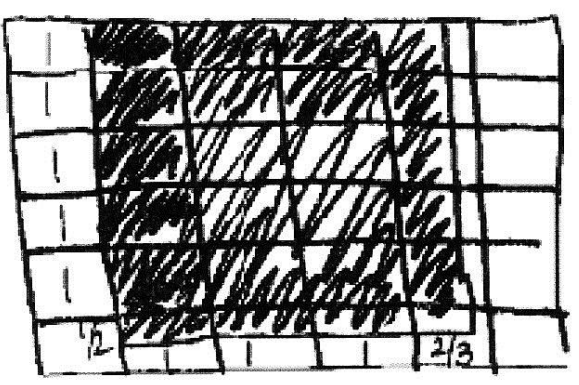

Figure 6. Visual model for representing $5 \frac{1}{2} \times 3 \frac{2}{3}$

\section{Relationship between Computational Ability and Representations Used}

In order to examine the relationship between PTs' computational abilities and representation used, Pearson correlations were computed. The results demonstrated that there were statistically significant ( 0.01 level, two-tailed) positive correlations among representational models used for comparison, addition and multiplication of fractions (i.e., $75 \% \times$ 32 ) and its computational processes. However, the correlation values of $0.296,0.253$ and 0.214 were weak and far from 1, showing that there was no meaningful relationship between computational and representational ability (Huck, 2008). The calculation and display (Figure 8) of confidence intervals showed statistically significant differences between PTs' computational ability and representational ability in multiplication and addition of fractions. 


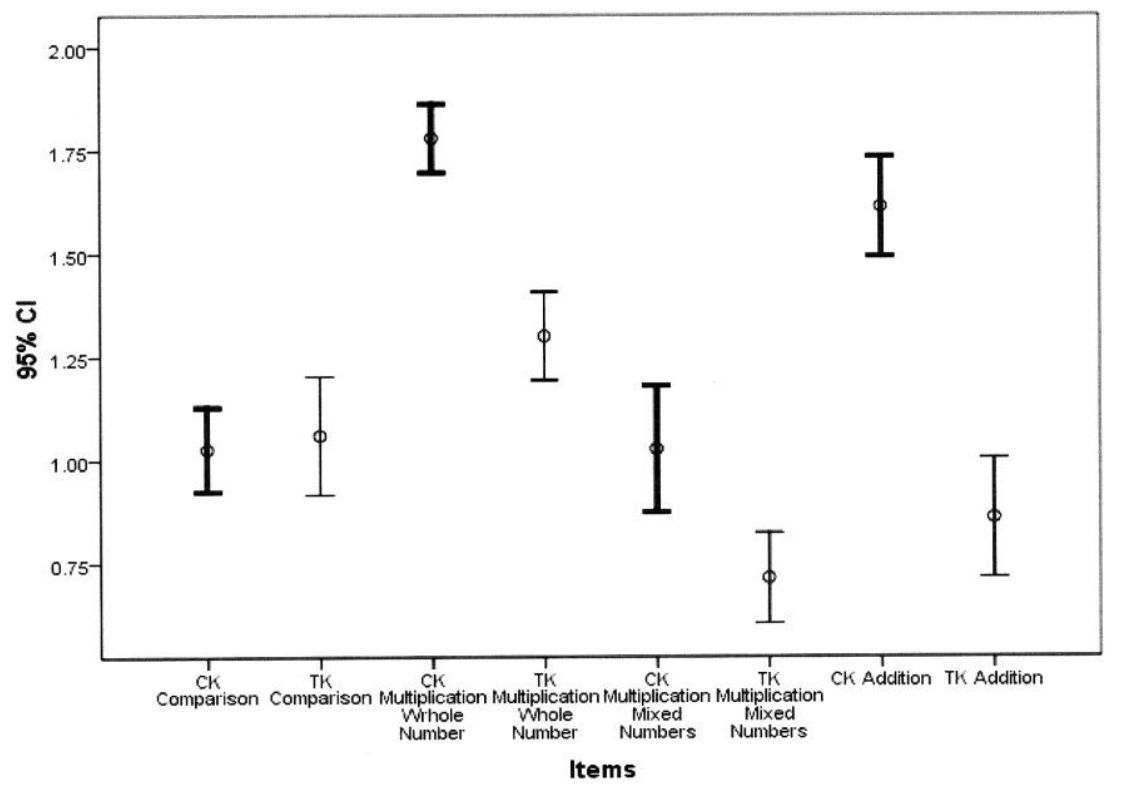

Note. $\mathbf{C K}=$ content knowledge; $\mathbf{T K}=$ teaching knowledge.

Figure 7. Means with $95 \%$ confidence interval of content and teaching knowledge

\section{DISCUSSION}

In general, the results indicate a big difference between PTs' knowledge of content and teaching knowledge. The results show that the PTs' content knowledge of fractions (i.e., adding, comparing, subtracting, and multiplying fractions) is greater than their teaching knowledge (i.e., representing computations of fractions). However, they had difficulty with multiplication of mixed numbers. The solution was generally conducted as if multiplying two separate numbers. For example they treated the 5 in $5 \frac{1}{2}$ as a whole number alone times the other whole number and then multiplied the two fractions' numerator by numerator and denominator by denominator. In contrast, students were more successful with the contextual problem (e.g. Johnny made a $75 \%$ on an exam with 32 questions. How many questions did he get correct?) that they may encounter more often that is a grading scenario. When considering knowledge for teaching fractions, the results show that the PTs performed better in algorithmic process of both multiplication types and addition compared to in their reasoning of fraction using representational models.

The evidence documented that PTs possess diverse computational ability when solving addition, subtraction, and multiplication of fractions. Even though addition and subtraction are inverse operations, nearly twice as many PTs answered in addition problem as 
compared to the subtraction of fractions. First of all, fractional addition can be easy for students because they learn addition earlier than subtraction and many students feel more comfortable with addition than subtraction. Another reason may be because the task used a story problem that provided a key word "together", which gave a clue to PTs for adding the two fractions. In fact, much classroom instruction has focusing on keyword and clue strategies for solving story problems such as "altogether" and "in all" for addition and "left" and "fewer" (Van de Walle, Karp \& Bay-Williams, 2010). On the other hand, many PTs might overlook the key word "difference" or could not connect it to subtraction when solving a non story problem. The researchers believed that teaching and learning mathematics should not focus on finding and memorizing key words for solving problems because students will not profoundly understand a particular operation.

The PTs' performance on multiplication tasks showed they had more difficulty solving $5 \frac{1}{2} \times 3 \frac{2}{3}$ as compared to $75 \% \times 32$. The two most common errors evidenced when solving the mixed number multiplication problems were (a) transforming mixed numbers into improper fractions or (b) directly multiplied both fractions as mixed numbers. One explanation might be that PTs memorized the rule for converting mixed numbers into improper fractions. In the latter case, it is possible that they over generalized the rule for multiplication of whole numbers and fractions. In addition, the results showed many PTs were able to compute $75 \% \times 32$ algorithmically. The performance differences between the two problems may be situated within application and computation realms. PTs rarely encounter mixed numbers outside the mathematics classroom whereas percents of wholes can be found in daily life activities such as shopping, discounts, and sporting events.

In regard to representational ability, many PTs could not provide an appropriate model demonstrating their conceptual understanding. PTs showed difficulties when representing multiplication of mixed numbers. In fact, the proportions of PTs who were able to use appropriate models in two multiplication tasks were mirror images of each other reflecting their insufficient understanding. In comparing fractions, PTs were able to represent one as larger than another using fraction strips; but many of them used different wholes in non-contextual problems as compared to contextual problems. When PTs were asked to draw a pictorial representation using the LCD, many were not able to show one unit whole and seven parts shaded of another unit whole. This showed PTs' inability to represent LCDs with a unit whole.

The results from this study contribute to our understanding that elementary PTs' knowledge of content and teaching fractions is not adequate. These fraction concepts are basic knowledge necessary for teaching elementary school mathematics (Van de Walle, Karp \& Bay-Williams, 2010), therefore, teacher educators needs to prepare PTs with adequate mathematical knowledge for teaching (Newton, 2008; Tirosh, 2000) as opposed to building algorithmic computation. It is critical to assess whether PTs have appropriate 
conceptual knowledge of fractions and are able to demonstrate this knowledge with representations, because concrete and pictorial representations are frequently used in elementary school classrooms. Teacher preparation programs should emphasize profound knowledge for teaching fractions using appropriate representational models. Teacher educators must be able to use a variety of instructional strategies to represent the concepts to enhance PTs' understanding (Empson, 2002; Shulman, 1986). In conclusion, teacher educators should focus on developing and enhancing PTs' conceptual understanding during classroom instruction in order to break the cycle of teaching and learning of fractions that are based on rote memorization and procedural computation (Cramer et al., 2002; Miller \& Hudson, 2006).

\section{REFERENCES}

Ball, D. L. (1990). The mathematical understandings that prospective teachers bring to teacher education. Elementary School Journal 90(4), 449-466.

Ball, D. L.; Hill, H. C. \& Bass, H. (2005). Knowing mathematics for teaching: Who knows mathematics well enough to teach third grade, and how can we decide? American Educator 29(3), $14-46$.

Ball, D. L.; Thames, M. H. \& Phelps, G. (2008). Content knowledge for teaching: What makes it special? Journal of Teacher Education 59(5), 389-407. doi: 10.1177/0022487108324554

Baumert, J.; Kunter, M.; Blum, W.; Brunner, M.; Voss, T.; Jordan, A.; Klusmann, U.; Krauss, S.; Neubrand, M. \& Tsai, Y. M. (2010). Teachers' mathematical knowledge, cognitive activation in the classroom, and student progress. American Educational Research Journal 47(1), 133-180.

Capraro, R. M.; Capraro, M. M.; Younes, R.; Han, S. Y. \& Garner, K. (2010). A longitudinal look at the equal sign through the lens of textbooks: A meta-analysis of relational symbols in K-12 textbooks. Paper presented at the annual meeting of the Southwest Educational Research Association held at New Orleans, LA; February 18, 2010.

Cramer, K.; Behr, M.; Post, T. \& Lesh, R. (1997). The rational number project: Fraction lessons for the middle grades, Level 1. Dubuque, IA: Kendall/Hunt.

Cramer, K. \& Wyberg, T. (2009). Efficacy of different concrete models for teaching the part-whole construct for fractions. Math. Think. Learn. 11(4), 226-257. ME 2011f.00421 doi: 10.1080/10986060903246479

Cramer, K. A.; Post, T. R. \& delMas, R. C. (2002). Initial fraction learning by fourth- and fifthgrade students: A comparison of the effects of using commercial curricula with the effects of using the rational number project curriculum. J. Res. Math. Educ. 33(2), 111-144. ME 2002c. 02128

Cumming, G. \& Finch, S. (2005). Inference by eye: Confidence intervals and how to read pictures 
of data. American Psychologist 60(2), 170-180. Retrieved from: http://www.apastyle.org/manual/related/cumming-and-finch.pdf

Diezmann, C. \& English, L. (2001). Promoting the use of diagrams as tools for thinking. In: A. Cuoco and F. Curcio (Eds.), The roles of representation in school mathematics. 2001 Yearbook of the National Council of Teachers of Mathematics (pp. 77-89). Reston, VA: National Council of Teachers of Mathematics.

Empson, S. B. (2002). Organizing diversity in early fraction thinking. In: B. Litwiller \& G. Bright (Eds.), Making sense of fractions, ratios and proportions. 2002 Yearbook of the National Council of Teachers of Mathematics (pp. 29-40). Reston, VA: National Council of Teachers of Mathematics.

Han, S. Y.; Rosli, R.; Capraro R. M. \& Capraro, M. M. (2011). The textbook analysis on probability: The case of Korea, Malaysia, and U. S. textbooks. J. Korea Soc. Math. Educ. Ser. D 15(2), 127-140.

Hill, H.; Rowan, B. \& Ball, D. L. (2005). Effects of teachers' mathematical knowledge for teaching on student achievement. American Education Research Journal, 42(2), 371-406. Retrieved from: http://deimos3.apple.com/WebObjects/Core.woa/FeedEnclosure/tamupublic.2117699024.02117699032.2276427372/enclosure.pdf

Huck, S. W. (2008). Reading statistics and research (5th edition) Boston, MA: Pearson Education.

Kiren, T. E. (1980). The rational number construct: Its elements and mechanisms. In: T. E. Kiren (Ed.), Recent research on number learning (pp. 125-149). Columbus, OH: Eric-SMEAC.

Koballa, T. R.; Glynn, S. M. \& Upson L. (2005). Conceptions of teaching science held by novice teachers in an alternative certification program. J. Sci. Teacher Educ. 16(4), 287-308. ME 2006e. 03303

Lamon, S. J. (1999). Teaching fractions and ratios for understanding: Essential content knowledge and instructional strategies for teachers. Mahwah, NJ: Erlbaum. ME 2001b.01827

Lamon, S. J. (2001). Presenting and representing from fractions to rational numbers. In: A. A. Cuoco \& F. R. Curcio (Eds.), The roles of representation in school mathematics (pp. 146-165). Reston, VA: The National Council of Teachers of Mathematics.

Ma, L. (1999). Knowing and teaching elementary mathematics: Teachers' understanding of fundamental mathematics in China and the United States. Mahwah, NJ: Erlbaum. ME 1999e.02385

Martin, S. \& Sebesta, L. (2004). Fractions: Building a foundation with concrete manipulatives. Illinois Schools Journal 83(2), 2-21.

Mewborn, D. S. (2003). Teaching, teachers' knowledge and their professional development. In: J. Kilpatrick, W. G. Martin \& D. Schifter (Eds.), A research companion to principles and standards for school mathematics (pp. 45-52). Reston, VA: National Council of Teachers of Mathematics. 
Miller, S. P. \& Hudson, P. J. (2006). Helping students with disabilities understand what mathematics means. Teaching Exceptional Children 39(1), 28-35. Retrieved from: http://elem-math.wiki.educ.msu.edu/file/view/12_Miller_TExcepCh06.pdf

Naiser, E. A.; Wright, W. E. \& Capraro, R. M. (2004). Teaching fractions: Strategies used for teaching fractions to middle grade students. Journal of Research in Childhood Education 18(3), 193-198.

National Assessment Educational Progress [NAEP] (2005). NAEP questions tools. Retrieved from: http://nces.ed.gov/nationsreportcard/itmrlsx/search.aspx?subject=mathematics

National Council of Teachers of Mathematics [NCTM] (2000). Principles and standards for school mathematics. Reston, VA: NCTM. ME 1999f.03937 for discussion draft (1998)

Newton, K. J. (2008). An extensive analysis of perservice elementary teachers' knowledge of fractions. American Educational Research Journal 45(4), 1080-1110. doi: 10.3102/0002831208320851

Patterson, J. M.; Capraro, R. M.; Kemp, G. P.; Standish, H. \& Sun, Y. (2003). The divergent child: Fraction concepts from their perspective. Paper presented at the 81st annual meeting of the National Council of Teachers of Mathematics held at San Antonio, TX; April, 2003.

Shulman, L. S. (1986). Those who understand: Knowledge growth in teaching. Educational Researcher 15(2), 4-14.

Simmons, P. E.; Emory, A.; Carter, T.; Coker, T.; Finnegan, B.; Crockett, D.; Richardson, L.; Yager, R.; Craven, J.; Tillotson, J.; Brunkhorst, H.; Twiest, M.; Hossain, K.; Gallagher, J.; DugganHaas, D.; Parker, J.; Cjas, R.;, Alshannag, Q.; McGlamery, S.; Krockover, J.; Adams, P.; Spector,B.; LaPorta, T.; James, B.; Rearden, K. \& Labuda, K. (1999). Beginning teachers: Beliefs and classroom actions. Journal of Research in Science Teaching 36(8), 930-945.

Skemp, R. (1976). Relational understanding and instrumental understanding. Math. Teaching 77(Dec.), 20-26. ME 19791.00120 for Arith. Teacher. (1978). 26(3), 9-15. [Reprinted from Math. Teaching 77(Dec. 1976)] Retrieved from: http://www.grahamtall.co.uk/skemp/pdfs/instrumental-relational.pdf

Tirosh, D. (2000). Enhancing prospective teachers' knowledge of children's conceptions: The case of division of fractions. J. Res. Math. Educ. 31(1), 5-25. ME 2000e.03419

Van de Walle, J. A.; Karp, K. S. \& Bay-Williams, J. M. (2010). Elementary and middle school mathematics: Teaching developmentally (7th ed.). Boston, MA: Pearson Allyn \& Bacon.

Vygotsky, L. (2009). Interaction between learning and development. In: M. Gauvain \& M. Cole (Eds.) Readings on the development of children (pp 42-48). New York, NY: Worth. [Reprinted from M. Cole, V. John-Steiner, S. Scribner and E. Souberman (Eds.) (1978), Mind in society: The development of higher psychological processes, (pp. 71-91) Cambridge, MA: Harvard University Press]

Wright, K. B. (2008). Assessing EC-4 preservice teachers' mathematics knowledge for teaching fractions concepts (Unpublished master's thesis). College Station, TX: Texas A\&M University. 


\section{APPENDIX A: INSTRUMENT ITEMS}

1. For the fractions $\frac{5}{7}$ and $\frac{2}{3}$, do the following: (make sure to show all your work).

(a) Show a process for comparing these two fractions.

(b) How would you show a student how to calculate the difference between these two fractions?

(c) Use the given representation of a geoboard or another representation to compare the fractions and clearly demonstrate if one is bigger.

2. Johnny made a $75 \%$ on an exam with 32 questions. How many questions did he get correct?

(a) Show your work as you would explain it to children.

(b) Draw and label a fraction strip to show how many questions he got correct.

3. Mark is building a desk. He has cut the top to measure 3 and $\frac{2}{3}$ feet in width and to measure 5 and $\frac{1}{2}$ feet in length.

(a) What is the area of the desk in square feet? (show all your work).

(b) Draw a visual representation for your solution.

4. Trey and Oriana each ordered a large pizza. Trey ate operation $\frac{5}{6}$ of his pizza and Oriana ate $\frac{3}{4}$ of her pizza.

(a) How much total pizza did they eat together? Show your work.

(b) Use fractions strips to compare how they ate. Who ate more?

(c) Represent, using the least common denominator, how much pizza they ate together using a pictorial representation. 


\section{APPENDIX B: CODING RUBRIC FOR FRACTION ASSESSMENT}

\section{Question 1a (Computation)}

\begin{tabular}{|c|c|l|}
\hline Points & Code & Categories \\
\hline \multirow{2}{*}{ 0-point } & 1 & No work shown/no solution \\
\cline { 2 - 3 } & 2 & Attempted but not appropriate/unequal unit wholes \\
\hline \multirow{3}{*}{ 1-point } & 3 & $\begin{array}{l}\text { Found one/two of these: CD, equivalent fractions, compare the } \\
\text { fractions }\end{array}$ \\
\cline { 2 - 3 } & 4 & $\begin{array}{l}\text { Model picture did not show comparison correctly (same unit } \\
\text { wholes)-pie chart/fraction strips }\end{array}$ \\
\cline { 2 - 3 } & 5 & No Computation, final answer only \\
\hline 2-point & 6 & Found CD and equivalent fractions to compare the fractions \\
\cline { 2 - 3 } & 7 & Model picture did show correct comparison /same unit wholes \\
\hline
\end{tabular}

\section{Question 1b (Computation)}

\begin{tabular}{|c|c|l|}
\hline Points & Code & Categories \\
\hline \multirow{2}{*}{ 0-point } & 1 & No work shown/no solution \\
\cline { 2 - 3 } & 2 & Attempted but not appropriate/verbal \\
\hline \multirow{2}{*}{ 1-point } & 3 & Found CD, equivalent fractions but did not find the difference \\
\cline { 2 - 3 } & 4 & Written responses either subtract/CD \\
\hline 2-point & 5 & Found CD, equivalent fractions and the difference of fractions \\
\hline & 6 & Written responses: find CD and subtract \\
\hline
\end{tabular}

\section{Question 1c (Representation)}

\begin{tabular}{|c|c|l|}
\hline Points & Code & Categories \\
\hline 0-point & 1 & No representation shown/no solution \\
\hline 1-point & 2 & Attempted but not appropriate/unequal unit wholes \\
\hline 2-point & 4 & $\begin{array}{l}\text { Same unit wholes but the representation did not show clearly which } \\
\text { one was bigger }\end{array}$ \\
\hline
\end{tabular}




\section{Question 2a (Computation)}

\begin{tabular}{|c|c|l|}
\hline Points & Code & Categories \\
\hline \multirow{3}{*}{ 0-point } & 1 & No work shown/no solution \\
\cline { 2 - 3 } & 2 & Attempted but not appropriate-e.g., 3 pts per question \\
\hline \multirow{4}{*}{ 1-point } & 3 & $\begin{array}{l}\text { Set up incorrect equation/ratio-used division rather than multiplica- } \\
\text { tion }\end{array}$ \\
\cline { 2 - 3 } & 4 & Set up an equation/ Drew a model picture \\
\cline { 2 - 3 } & 5 & Did not subtract 8Qs from 32 Qs \\
\hline \multirow{5}{*}{ 2-point } & 6 & $\begin{array}{l}\text { Converted into ratio/fraction/decimal and set up an equation cor- } \\
\text { rectly for answer-subtracted 8 Qs from 32 Qs }\end{array}$ \\
\cline { 2 - 3 } & 7 & $\begin{array}{l}\text { Converted into ratio/fraction/decimal and set up an equation cor- } \\
\text { rectly for answer-direct multiplication }\end{array}$ \\
\cline { 2 - 3 } & 8 & $\begin{array}{l}\text { Used percentage and set up an equation correctly for answer - } \\
\text { subtracted 8 Qs from 32 Qs }\end{array}$ \\
\cline { 2 - 3 } & 9 & Set up correctly an equation using ratio and solve for x \\
\cline { 2 - 3 } & 10 & Divided 32 by 4, then multiplied answer by 3 or minus 8 \\
\cline { 2 - 3 } & 11 & Proportional reasoning \\
\hline
\end{tabular}

\section{Question 2b (Representation)}

\begin{tabular}{|l|c|l|}
\hline Points & Code & Categories \\
\hline \multirow{2}{*}{ 0-point } & 1 & No representation shown/no solution \\
\cline { 2 - 3 } & 2 & Attempted but not appropriate \\
\hline \multirow{3}{*}{ 1-point } & 3 & Did not shade 3/4 or 24/32 parts/ shaded more or less parts \\
\cline { 2 - 3 } & 4 & Used a fraction strip with 3/4 area shaded \\
\cline { 2 - 3 } & 6 & Shaded appropriate parts without appropriate labeling \\
\cline { 2 - 3 } & 7 & Use number line \\
\hline 2-point & 5 & Used a fraction strip with 24/32 area shaded \\
\hline
\end{tabular}

\section{Question 3a (Computation)}

\begin{tabular}{|c|c|l|}
\hline Points & Code & Categories \\
\hline \multirow{2}{*}{ 0-point } & 1 & No work shown/no solution \\
\cline { 2 - 3 } & 2 & Attempted but not appropriate \\
\hline \multirow{3}{*}{ 1-point } & 3 & Used incorrect improper fraction, lead to wrong answer \\
\cline { 2 - 3 } & 4 & Used correct improper fractions but error answer (simplify) \\
\cline { 2 - 3 } & 5 & No Computation, final answer only \\
\hline 2-point & 6 & Used correct improper fractions for multiplication, correct answer \\
\hline
\end{tabular}

\section{Question 3b (Representation)}

\begin{tabular}{|c|c|l|}
\hline Points & Code & Categories \\
\hline \multirow{2}{*}{ 0-point } & 1 & No representation shown/no solution \\
\cline { 2 - 3 } & 2 & Attempted but not appropriate-length and width \\
\hline 1-point & 3 & Drew a rectangle without showing any partitions \\
\hline 2-point & 4 & Drew a rectangle and showed correct partitions \\
\hline
\end{tabular}




\section{Question 4a (Computation)}

\begin{tabular}{|c|c|l|}
\hline Points & Code & Categories \\
\hline \multirow{2}{*}{ 0-point } & 1 & No work shown/no solution \\
\cline { 2 - 3 } & 2 & $\begin{array}{l}\text { Attempted but not appropriate-e.g.: incorrect because added nu- } \\
\text { merators and denominators }\end{array}$ \\
\hline 1-point & 3 & $\begin{array}{l}\text { Found only one/two of these: CD/LCD, equivalent fractions, total } \\
\text { pizza eaten }\end{array}$ \\
\hline & 4 & No Computation, final answer only \\
\hline 2-point & 5 & $\begin{array}{l}\text { Found CD (not necessary LCD), equivalent fractions, and total } \\
\text { fractions }\end{array}$ \\
\hline & 6 & Model picture did show correct addition /same unit wholes \\
\hline
\end{tabular}

\section{Question 4b (Representation)}

\begin{tabular}{|c|c|l|}
\hline Points & Code & Categories \\
\hline \multirow{2}{*}{ 0-point } & 1 & No work shown/no solution \\
\cline { 2 - 3 } 1-point & 2 & Attempted but not appropriate \\
\hline \multirow{2}{*}{ 2-point } & 3 & $\begin{array}{l}\text { Used fractions strips with same unit wholes but did not show Trey } \\
\text { ate more }\end{array}$ \\
\hline & 5 & $\begin{array}{l}\text { Used fractions strips with unequal unit wholes } \\
\text { Trey ate more }\end{array}$ \\
\hline
\end{tabular}

\section{Question 4c (Representation)}

\begin{tabular}{|c|c|l|}
\hline Points & Code & Categories \\
\hline \multirow{2}{*}{ 0-point } & 1 & No representation shown/no solution \\
\cline { 2 - 3 } 1-point & 2 & Attempted but not appropriate-unequal unit wholes \\
\hline \multirow{2}{*}{ 2-point } & 3 & $\begin{array}{l}\text { Same unit wholes but did not use the least common denominator } \\
(10 / 12+9 / 12)\end{array}$ \\
\cline { 2 - 3 } & 5 & $\begin{array}{l}\text { Same unit wholes, some part were not equal } \\
\text { whole }\end{array}$ \\
\hline
\end{tabular}

